\title{
Solar Elastosis in Its Papular Form: Uncommon, Mistakable
}

\author{
Jun Khee Heng Derrick Chen Wee Aw Kong Bing Tan \\ National University Hospital, Singapore, Singapore
}

\section{Key Words}

Papular elastosis · Photoaging · Solar elastosis · Ultraviolet rays

\begin{abstract}
Solar elastosis is a degenerative condition of elastic tissue in the dermis due to prolonged sun exposure. There are a variety of clinical manifestations of solar elastosis. In its most common form, solar elastosis manifests as yellow, thickened, coarsely wrinkled skin. We report two uncommon cases of severe solar elastosis with a papular morphology. Its presentation can closely mimic a host of cutaneous disorders and thus, although it is helpful to be cognizant of this entity, it is still crucial to biopsy these lesions to avoid missing a more sinister condition.

(C) 2014 S. Karger AG, Basel
\end{abstract}

\section{Introduction}

Solar elastosis refers to histopathologic changes in degenerative dermal elastic tissue that occurs in photodamaged skin. The predominant histological feature of solar elastosis is basophilic degeneration of elastotic fibers in the dermis, separated from the epidermis by a narrow band of normal-appearing collagen (grenz zone) with collagen fibers arranged horizontally [1]. The degree of elastosis correlates with the cumulative amount of ultraviolet radiation to which the skin has been exposed [2].

Several distinct clinicopathological entities of solar elastosis have been described [3]. These are distinguished by a combination of anatomic location, clinical appearance, and histopathologic findings. Otherwise, the other clinical patterns which are histologically similar are usually grouped together under the term 'solar elastosis' [4]. Solar elastotic syndromes include solar elastosis, Favre-Racouchot syndrome, elastotic nodules of the ears, collagenous and elastotic plaques of the hands and colloid milia [4-10]. Here we present two patients with a rare clinical presentation of solar elastosis in the papular form. 


\section{Case 1}

A 55-year-old Chinese man was referred to our clinic for regular screening for skin cancer. He had a history of diabetes mellitus, hypertension and had received a kidney transplant more than 10 years ago. Current medications include prednisolone and mycophenolate mofetil.

Physical examination revealed three similar pearly telangiectatic red-brown firm papules on the nose and right nasal philtrum (fig. 1). Each measured $5 \mathrm{~mm}$ in diameter. The lesions were asymptomatic and had been present for 2 months. A 3-mm punch biopsy of a representative lesion was performed.

Histological evaluation of the skin showed marked solar elastosis with non-specific patchy chronic lymphoplasmacytic infiltrate (fig. 2). There was no evidence of malignancy on examination of multiple sections of tissue.

\section{Case 2}

A 75-year-old Chinese man, on regular follow-up for psoriasis, presented with a 1month history of a bump on the face which bled a little with scratching. Moreover, he had a history of ischemic heart disease, hypertension, hyperlipidemia, diabetes mellitus and hypoadrenalism secondary to exogenous steroid use in the past. Current medications include oral methotrexate and prednisolone in replacement dose.

Physical examination revealed a 3-mm skin-colored papule on the left philtrum (fig. 3). He had extensive photodamaged skin with multiple actinic keratoses on his scalp.

The lesion was excised and its histology revealed extensive solar elastosis. There was mild epidermal acanthosis with no evidence of tumor on examination of multiple tissue sections.

\section{Discussion and Review of the Literature}

In our two cases, the histological findings were consistent with severe solar elastosis. It appears to be uncommon for solar elastosis to manifest in a papular form and very often, it can resemble other skin disorders. Some of the mimics of papular solar elastosis include basal cell carcinoma, sebaceous hyperplasia, molluscum contagiosum and actinic keratosis.

Papular elastosis is a term that was first proposed by Kwittken [11] in 2000. He described the skin lesions as asymptomatic, shiny, smooth, firm papules, 1-10 $\mathrm{mm}$ in diameter, that can be multiple or solitary, with various colorations. Histological examination shows severe elastosis involving most of the papillary cutis. He reported two cases of papular elastosis and since then there has been no other literature found with regards to this unique presentation of solar elastosis.

The commonest solar elastotic syndrome is solar elastosis. It presents as thick, dry, coarsely wrinkled skin with loss of skin tone. One of the most well recognized clinical variant is cutis rhomboidalis nuchae, in which there is thickened yellow leathery-appearing skin at the posterolateral aspect of the neck. The origin of the elastotic material in the dermis has been postulated to be due to degradation of collagen and/or elastic fibers, overactive sundamaged fibroblast synthesizing new elastic tissue, and an abnormal synthetic and degradative process [4]. 
In Favre-Rachouchot syndrome, thickened yellow plaques with follicular cysts surrounded by multiple open comedones are typical. The skin around the eyes is a usual site, and the condition occurs more commonly in older men. Histological examination shows increased elastic tissue with thickened, tortuous fibers in the upper and mid dermis. There are dilated comedones and follicular plugging with keratinous debris in the lumen [5].

Elastotic nodule(s) of the ear is characterized by single or multiple bilateral, firm to hard pale nodules on the antihelix or helix. Histological features include irregular coarse, elastotic material and clumped masses of thick fibers on a background of marked solar elastosis [6]. The fibers and clumps can be best seen with elastic-Van Gieson stain. Clinically, they may resemble basal cell carcinoma, amyloidosis, gouty tophi and chondrodermatitis nodularis helicis.

Collagenous and elastotic plaques of the hands is a slowly progressive condition more often found in older men with waxy linear plaques at the junction of the dorsal and palmar skin on the hand [7]. Histological examination shows amorphous basophilic elastotic masses and thickened, fragmented, calcified elastic fibers in the upper and mid dermis. The thick collagen bundles have a haphazard arrangement, but with a proportion running perpendicular to the surface [8].

Adult colloid milium, another solar elastotic dermatosis, is the closest clinical differential diagnosis of papular elastosis. Light microscopy shows accumulation of a homogenous, amorphous faintly eosinophilic material with cleft-like spaces in the upper and mid dermis. The cause for the colloid deposition in the dermis is still uncertain, but some authors have suggested that it is from degeneration of collagen and/or elastic fibers due to actinic action [9]. There is also a possibility that this elastotic material is newly formed from sun-damaged fibroblast [10].

Interestingly, both our patients were on immunosuppressive therapy and they both had dual agents. There is strong evidence that organ transplant recipients on immunosuppressive therapy have an increased risk of actinic damage and skin cancers [12-14]. It has also been reported that transplant recipients with a history of skin cancer may experience a deceleration of cutaneous carcinogenesis after stopping immunosuppressants [15]. Further research work is needed to elucidate the molecular mechanisms of immunosuppression leading to an acceleration of solar elastosis.

In summary, we have presented two cases of papular elastosis that occurs in chronically sun-damaged skin. It is necessary to obtain biopsy confirmation as this condition is very rare, and important differential diagnoses such as basal cell carcinoma need to be ruled out. The most effective strategy to manage solar elastosis is prevention of actinic-related damage with sun avoidance, protective clothing and sunscreen.

\section{References}

1 Lewis KG, Bercovitch L, Dill SW, Robinson-Bostom L: Acquired disorders of elastic tissue. 1. Increased elastic tissue and solar elastotic syndromes. J Am Acad Dermatol 2004;51:1-21.

-2 Kligman AM: Early destructive effect of sunlight on human skin. JAMA 1969;210:2377-2380.

3 Salasche SJ, Clemons DE: Cutaneous manifestations of chronic solar exposure. J Assoc Milit Dermatol 1985;11:3-10.

4 Calderone DC, Fenske NA: The clinical spectrum of actinic elastosis. J Am Acad Dermatol 1995;32:10161024.

5 Patterson WM, Fox MD, Schwartz RA: Favre-Racouchot disease. Int J Dermatol 2004;43:167-169.

6 Weedon D: Elastotic nodules of the ear. J Cutan Pathol 1981;8:429-433.

7 Kocsard E: Keratoelastoidosis marginalis of the hands. Dermatologica 1965;131:169-175.

8 Burks JW, Wise LJ, Clark WH: Degenerative collagenous plaques of the hands. Arch Dermatol 1960;82:362366. 
Heng et al.: Solar Elastosis in Its Papular Form: Uncommon, Mistakable

-9 Innocenzi D, Barduagni F, Cerio R, Wolter M: UV-induced colloid milium. Clin Exp Dermatol 1993;18:347350.

10 Hashimoto K, Black M: Colloid milium: a final degeneration product of actinic elastoid. J Cutan Pathol 1985;12:147-156.

11 Kwittken J: Papular elastosis. Cutis 2000;66:81-83.

12 Berg D, Otley CC: Skin cancer in organ transplant recipients: epidemiology, pathogenesis, and management. J Am Acad Dermatol 2002;47:1-17.

13 Hartevelt MM, Bouwes Bavinck JN, Kootte AM, et al: Incidence of skin cancer after renal transplantation in The Netherlands. Transplantation 1990;49:506-509.

14 Bordea C, Wojnarowska F, Millard PR, et al: Skin cancers in renal-transplant recipients occur more frequently than previously recognized in a temperate climate. Transplantation 2004;77:574-579.

15 Otley CC, Coldiron BM, Stasko T, Goldman GD: Decreased skin cancer after cessation of therapy with transplant-associated immunosuppressants. Arch Dermatol 2001;137:459-463.

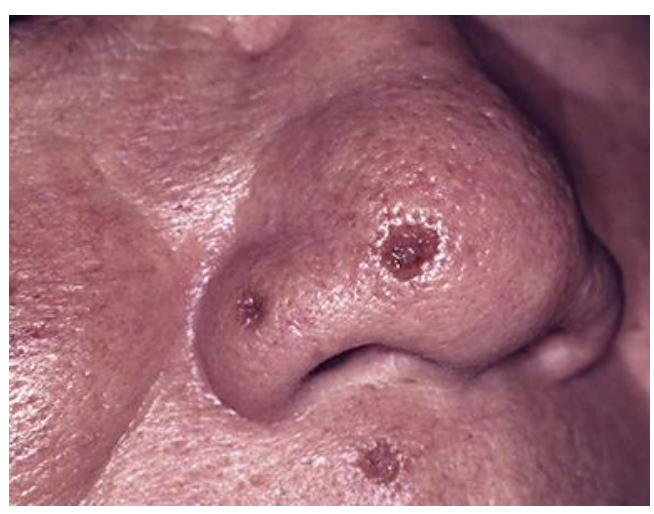

Fig. 1. Solar elastosis. Three papules over the nose and right philtrum.

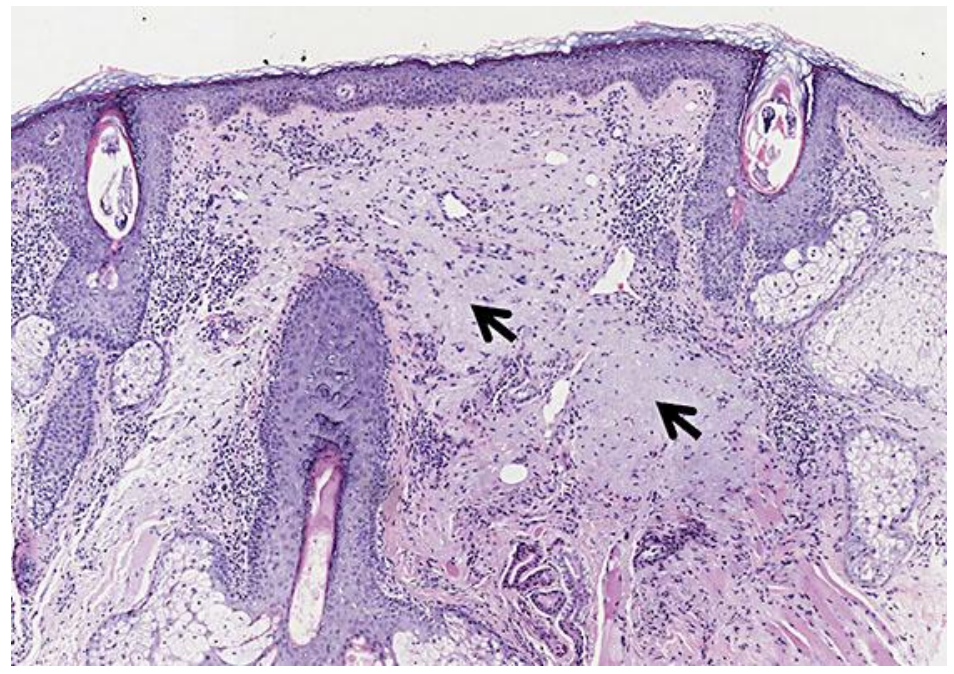

Fig. 2. Solar elastosis (arrows) and mild periadnexal and perivascular infiltrate of lymphocytes. HE. Original magnification $\times 40$. 


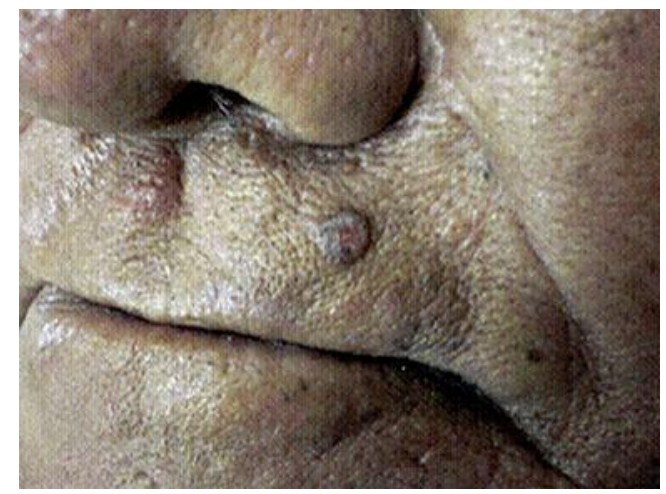

Fig. 3. Solar elastosis. Papule over the left philtrum. 